\title{
Clinical Outcomes of ABO-Incompatible Kidney Transplantation in Patients with End-Stage Kidney Disease due to Diabetes Nephropathy
}

\author{
Junji Uchida ${ }^{a} \quad$ Akihiro Kosoku $^{a} \quad K^{2}$ Kazuya Kabei ${ }^{a}$ Shunji Nishide ${ }^{a}$ \\ Hisao Shimada ${ }^{a}$ Tomoaki Iwai ${ }^{a}$ Nobuyuki Kuwabara ${ }^{a}$ Toshihide Naganuma ${ }^{a}$ \\ Keiko Maeda ${ }^{b}$ Norihiko Kumada ${ }^{c}$ Yoshiaki Takemoto ${ }^{a}$ Tatsuya Nakatani $^{a}$ \\ ${ }^{a}$ Department of Urology, Osaka City University Graduate School of Medicine, Osaka, Japan; b Department of Nursing, \\ Osaka City University Hospital, Osaka, Japan; ' Department of Urology, Suita Municipal Hospital, Suita, Japan
}

\section{Keywords}

Kidney transplantation · ABO-incompatible $\cdot$ Diabetes

mellitus

\begin{abstract}
Background: Diabetes nephropathy is one of the most common causes of end-stage kidney disease (ESKD) worldwide. The data are clear that kidney transplantation is superior to remaining on dialysis for patients with diabetes. However, there have been no reports on $A B O$-incompatible kidney transplantation in patients with ESKD due to diabetes nephropathy. Patients and Methods: We conducted a retrospective, observational study to investigate the clinical outcomes of ABO-incompatible kidney transplantation for patients with pre-existing diabetes nephropathy at our institution from April 2011 to October 2017. A total of 14 recipients were enrolled in this study. Results: All 14 patients underwent successful kidney transplantation. Both overall patient and graft survival rates were $100,89.9$, and $89.9 \%$ at 1,3 , and 5 years, respectively. One patient died 20 months after transplantation with a functioning graft due to pancreas cancer. Two of the 14 patients (14.3\%) developed biopsyproven acute cellular rejection during the follow-up period. The median observation period was 32.0 months (range
\end{abstract}

\begin{tabular}{ll}
\hline KARGER & $\begin{array}{l}\text { (c) } 2019 \text { The Author(s) } \\
\text { Published by S. Karger AG, Basel }\end{array}$ \\
E-Mail karger@karger.com & This article is licensed under the Creative Commons Attribution- \\
www.karger.com/uin & $\begin{array}{l}\text { NonCommercial-NoDerivatives 4.0 International License (CC BY- } \\
\text { NC-ND) (http://www.karger.com/Services/OpenAccessLicense). } \\
\text { Usage and distribution for commercial purposes as well as any dis- } \\
\text { tribution of modified material requires written permission. }\end{array}$
\end{tabular}

5-83 months). Conclusion: ABO-incompatible kidney transplantation may be an acceptable renal replacement therapy for ESKD patients with diabetes.

(c) 2019 The Author(s)

Published by S. Karger AG, Basel

\section{Introduction}

While a steady decline in mortality rates among patients with type 2 diabetes has been observed over time in the general population, outcomes of kidney transplantation in patients with diabetes remain inferior compared with those of non-diabetic recipients [1]. Kidney transplant recipients with diabetes have a higher mortality than those without diabetes because of their elevated incidence of risk complications such as cardiovascular disease and infection [2,3]. Moreover, a recent report demonstrated that pre-existing diabetes is a risk factor for increased rates of cellular rejection after kidney transplantation [4]. However, the data are clear that kidney transplantation is superior to remaining on dialysis for patients with diabetes [5].

In Japan, due to the severe shortage of deceased donors, the number of $\mathrm{ABO}$-incompatible kidney transplantation is currently increasing, accounting for more 
than $30 \%$ of all living donor kidney transplants. Although it is considered to be an immunologically high-risk procedure, excellent outcomes have been achieved [6-9]. Diabetes nephropathy is one of the most common causes of end-stage kidney disease (ESKD) worldwide and is the most frequent cause of ESKD in Japan. However, there have been no reports on $\mathrm{ABO}$-incompatible kidney transplantation for patients who developed ESKD due to diabetes nephropathy. In the present pilot study, we summarized our experience with ABO-incompatible kidney transplantation in ESKD patients with diabetes.

\section{Patients and Methods}

We conducted a retrospective, observational study to investigate our clinical experience with $\mathrm{ABO}$-incompatible kidney transplantation in patients with ESKD due to diabetes nephropathy at our institution, focusing on the rates of acute cellular rejection and antibody-mediated rejection, complications, and patient and graft survivals. A total of 140 patients underwent living donor kidney transplantation at our institution from April 2011 to October 2017, of which 46 recipients received $\mathrm{ABO}$-incompatible donor grafts. Among them, there were 14 patients with pre-existing diabetes nephropathy, and these patients were followed up until April 2018. The diagnosis of diabetes nephropathy was confirmed by a nephrologist as well as preexisting diabetic retinopathy [10].

Desensitization protocols for ABO-incompatible kidney transplantation have been developed over time, and we have utilized the optimal protocol available at the time. Our protocols have been described previously [9, 11-17]. Briefly, as our present standard desensitization protocol to remove the anti-A/B antibodies, the patients underwent plasmapheresis prior to kidney transplantation until the antibody titers were less than 1:16. The patients received 1 (before December 2011) or 2 doses (after January 2012) of rituximab $\left(150 \mathrm{mg} / \mathrm{m}^{2}\right)$ prior to transplantation to inhibit antibody production [16]. Pretransplant desensitization consisted of administration of 2 weeks (after January 2012) or 4 weeks (before December 2011) of mycophenolate mofetil (MMF) 0.5-1.0 g/day or everolimus $1.5 \mathrm{~g}$ /day for B-cell lymphocyte suppression. Basic immunosuppression after transplantation consisted of basiliximab, steroid, calcineurin inhibitors (cyclosporine [CsA] or tacrolimus [Tac]), and MMF or everolimus. In the immunosuppression regimen with everolimus, the dose was adjusted to target CsA trough levels of $100-200 \mathrm{ng} / \mathrm{mL}$ at $0-2$ months, $75-150 \mathrm{ng} / \mathrm{mL}$ at 2-4 months, $50-100 \mathrm{ng} / \mathrm{mL}$ at $4-6$ months, and $25-50 \mathrm{ng} / \mathrm{mL}$ at more than 6 months after transplant, and to target Tac trough levels of $4-7 \mathrm{ng} / \mathrm{mL}$ at $0-6$ months and $2-4 \mathrm{ng} / \mathrm{mL}$ at more than 6 months after transplant. In the immunosuppression regimen with MMF, the dose was adjusted to target CsA trough levels of 200-250 $\mathrm{ng} / \mathrm{mL}$ at $0-1$ month, $150-200 \mathrm{ng} / \mathrm{mL}$ at $1-2$ months, $100-150 \mathrm{ng} /$ $\mathrm{mL}$ at $2-3$ months, and $80-120 \mathrm{ng} / \mathrm{mL}$ at more than 3 months after transplant, and to target Tac trough levels of $8-12 \mathrm{ng} / \mathrm{mL}$ at $0-1$ month, $8-10 \mathrm{ng} / \mathrm{mL}$ at $1-2$ months, $6-8 \mathrm{ng} / \mathrm{mL}$ at $2-3$ months, and $5-8 \mathrm{ng} / \mathrm{mL}$ at more than 3 months after transplant. Our desensitization protocol was modified depending on age $[13,14]$, rebound of antibody titers, or baseline antibody titer. In cases that seemed to be high risk, additional desensitization was performed to avoid antibody-mediated rejection by anti-A/B antibodies. The patients with anti-A/B antibody titers of more than 1:1048 received 2 doses of rituximab $\left(150 \mathrm{mg} / \mathrm{m}^{2}\right)$ and additionally underwent splenectomy (case 1 and 3) [15]. This study was approved by the Ethics Committee of Osaka City University Graduate School of Medicine (No. 3957). Opt-out consent was obtained instead of written informed consent. We provided patients with information explaining the proposed research plan (the purpose, required individual data, and duration of research) by means of an information website of our hospital and gave them the opportunity of opt-out. All the procedures were in accordance with the Helsinki Declaration of 2000 and the Declaration of Istanbul 2008.

For treatment of acute cellular rejection episodes, methylprednisolone was administered at a dose of $500 \mathrm{mg}$ /day for 3 days alone or in combination with deoxyspergualin $(5 \mathrm{mg} / \mathrm{kg} /$ day: $5-7$ days). When resistance to these drugs was confirmed, anti-human thymocyte immunoglobulin was administered. For treatment of antibodymediated rejection, plasmapheresis was performed, and rituximab was administered. Acute cellular rejection and antibody-mediated rejection were histologically diagnosed by light microscopy of graft biopsy specimens according to the Banff 2007-2013 criteria. Surveillance biopsies were performed once before discharge from hospital, which was a month after surgery for most patients, or within 3 months after surgery in all patients. When clinically indicated by rising serum creatinine or decreasing urine output, episode biopsies were performed. Anti-A/B antibody titers were measured pre- and post-transplantation. The saline agglutination technique was used for the measurement of anti-IgM titers, and the indirect Coombs' test was used for the measurement of anti-IgG titers.

\section{Results}

\section{Patient Characteristics (Table 1)}

The mean age of the recipients and donors at transplantation was $54.6 \pm 10.5$ and $54.2 \pm 11.1$ years, respectively. The median HLA mismatches were 3.5 antigens (0-6 antigens). The mean dialysis duration was $16.4 \pm$ 16.2 months. Four recipients $(28.6 \%)$ enrolled in this study had experienced cardiovascular disease. All patients had pre-existing type 2 diabetes and no patients had type 1 diabetes in this study. The mean diabetes duration was $19.3 \pm 7.21$ months, and all recipients had diabetic retinopathy. The median observation period was 32.0 months (range 5-83 months). No patient had pre-formed donor-specific antibodies before transplantation by the panel reactive antibody screening test. The patient characteristics are given in Table 1.

\section{Desensitization (Table 2)}

Our standard desensitization protocol for ABO-incompatible kidney transplantation is shown in Figure 1. The median initial anti-A/B IgG and IgM titers were 1:16 (1:2-1:2048) and 1:16 (1:2-1:512), respectively. The me- 
Table 1. Patient characteristics

\begin{tabular}{|c|c|c|c|c|c|c|c|c|c|c|c|}
\hline Case & Gender & $\begin{array}{l}\text { Age at } \\
\text { transplant, } \\
\text { years }\end{array}$ & $\begin{array}{l}\text { Donor } \\
\text { relation }\end{array}$ & $\begin{array}{l}\text { Donor } \\
\text { age, } \\
\text { years }\end{array}$ & $\begin{array}{l}\text { Dialysis } \\
\text { duration, } \\
\text { months }\end{array}$ & $\begin{array}{l}\text { HLA } \\
\text { mismatch } \\
\text { (antigen) }\end{array}$ & $\begin{array}{l}\text { Initial anti-A/B } \\
\text { antibody titer } \\
\text { (IgG) }\end{array}$ & $\begin{array}{l}\text { Initial anti-A/B } \\
\text { antibody titer } \\
\text { (IgM) }\end{array}$ & $\begin{array}{l}\text { Cardiovascular disease } \\
\text { history }\end{array}$ & $\begin{array}{l}\text { Diabetes } \\
\text { duration, } \\
\text { years }\end{array}$ & $\begin{array}{l}\text { Diabetic } \\
\text { retinopathy } \\
\text { history }\end{array}$ \\
\hline 1 & M & 57 & Wife & 55 & 9 & 2 & 1,024 & 64 & & 23 & + \\
\hline 2 & M & 49 & Wife & 52 & 3 & 5 & 64 & 8 & Brain infarction & 15 & + \\
\hline 3 & M & 55 & Wife & 56 & 26 & 6 & 8,192 & 256 & & 13 & + \\
\hline 4 & $\mathrm{~F}$ & 64 & Husband & 59 & 9 & 4 & 512 & 256 & Angina pectoris & 23 & + \\
\hline 5 & $\mathrm{~F}$ & 69 & Wife & 69 & 9 & 3 & 8 & 16 & & 27 & + \\
\hline 6 & $\mathrm{~F}$ & 33 & Uncle & 58 & 23 & 2 & 16 & 32 & & 13 & + \\
\hline 7 & M & 65 & Wife & 63 & 54 & 4 & 64 & 64 & $\begin{array}{l}\text { Arteriosclerosis obliterans, } \\
\text { myocardial infarction }\end{array}$ & 35 & + \\
\hline 8 & M & 62 & Son & 30 & 43 & 2 & 8 & 16 & Angina pectoris & 23 & + \\
\hline 9 & $\mathrm{M}$ & 51 & Wife & 49 & 24 & 4 & 8 & 16 & & 17 & + \\
\hline 10 & M & 66 & Wife & 74 & 0 & 3 & 64 & 64 & & 16 & + \\
\hline 11 & $\mathrm{M}$ & 53 & Wife & 51 & 16 & 4 & 4 & 4 & & 14 & + \\
\hline 12 & $\mathrm{M}$ & 51 & Wife & 49 & 8 & 4 & 32 & 32 & & 16 & + \\
\hline 13 & $\mathrm{~F}$ & 37 & Husband & 39 & 0 & 2 & 32 & 32 & & 28 & + \\
\hline 14 & M & 53 & Brother & 55 & 5 & 0 & 8 & 8 & & 7 & + \\
\hline
\end{tabular}

Table 2. Desensitization

\begin{tabular}{rlllll}
\hline Case & $\begin{array}{l}\text { CNI } \\
\text { (CsA/Tac) }\end{array}$ & $\begin{array}{l}\text { MMF/ } \\
\text { everolimus }\end{array}$ & $\begin{array}{l}\text { Dose of } \\
\text { rituximab }\end{array}$ & $\begin{array}{l}\text { Number of } \\
\text { plasmapheresis }\end{array}$ & Splenectomy \\
\hline 1 & CsA & MMF & 2 & 8 & - \\
2 & CsA & MMF & 2 & 4 & + \\
3 & Tac & MMF & 2 & 13 & - \\
4 & CsA & MMF & 1 & 3 & - \\
5 & CsA & MMF & 1 & 3 & - \\
6 & CsA & MVR & 1 & 3 & - \\
7 & Tac & MMF & 1 & 5 & - \\
8 & CsA & MMF & 1 & 2 & - \\
9 & Tac & Mac & 1 & 4 & - \\
10 & Tac & MMF & 1 & 2 & - \\
11 & Tac & MMF & 1 & 4 & - \\
12 & Tac & MMF & 1 & 2 & - \\
13 & MMF & 1 & 1 & \\
\end{tabular}

CNI, calcineurin inhibitor; CsA, cyclosporine; Tac, tacrolimus; MMF, mycophenolate mofetil.

dian number of plasmapheresis sessions prior to transplantation was $3(1-13)$. Three patients received 2 doses of rituximab, and the others received a single dose of rituximab. Two recipients underwent splenectomy and rituximab administration due to high anti-A/B antibody titers. As pretransplant desensitization for $\mathrm{B}$ cell depletion, 12 received MMF and 2 received everolimus. After desensitization, anti-A/B IgG and IgM antibody titers before transplantation decreased to below 1:16 in all cases.
Postoperative anti-A/B antibody titers remained suppressed without plasmapheresis. All the recipients experienced no significant post-operative anti-A/B antibody titer elevation causing antibody-mediated rejection.

\section{Patient and Graft Survivals (Table 3)}

All 14 patients underwent successful kidney transplantation. Both overall patient and graft survival rates were $100,89.9$, and $89.9 \%$ at 1,3 , and 5 years, respectively. 




Fig. 1. Immunosuppressive protocol for standard ABO-incompatible kidney transplantation. MMF, mycophenolate mofetil.

Death-censored graft survival rates were $100 \%$ at 5 years. One patient died 20 months after transplantation with a functioning graft due to pancreas cancer. The other 13 patients did not experience graft loss or death after transplantation and maintained good graft functions. The mean estimated glomerular filtration rate was $44.8 \pm 12.1$ $\mathrm{mL} / \mathrm{min} / 1.73 \mathrm{~m}^{2}$.

\section{Changes in Diabetes Treatment and HbAlc}

Two patients received no treatment, 4 received antidiabetic drugs, 3 received both anti-diabetic drugs and insulin therapy, and 5 received insulin therapy for treatment of diabetes at transplantation. The mean values of body mass index and $\mathrm{HbAlc}$ levels were $26.7 \pm 3.3 \mathrm{~kg} / \mathrm{m}^{2}$ and $6.2 \pm 0.9 \%$ at transplantation, respectively. After transplantation, all recipients required insulin therapy, and 2 were administered with additional anti-diabetic drugs such as sodium glucose co-transporter 2 inhibitors and glinide. The mean values of body mass index and $\mathrm{HbA} 1 \mathrm{c}$ levels were $27.3 \pm 4.2 \mathrm{~kg} / \mathrm{m}^{2}$ and $6.9 \pm 0.5 \%$ at the end of follow-up period, respectively. There were no significant differences in body mass index and $\mathrm{HbAlc}$ between at transplant and the end of the follow-up period.

\section{Rejections (Table 3)}

Two of the 14 patients (14.3\%) developed Banff IA biopsy-proven acute cellular rejection during the follow-up period. One patient was diagnosed with Banff IA ( $t 2$, i1, $\mathrm{g} 0$, v0, ptc1, c4d[-]) by surveillance biopsy before discharge and another was diagnosed with Banff IA (t2, i2, g0, v0, ptc1, c4d[-]) by episode biopsy, when serum creatinine level increased and acute rejection was suspected 3 months after transplant. Both patients were successfully treated with steroid-pulse therapy and administration of deoxyspergualin. There were no changes in glomerulosclerosis, interstitial fibrosis, and tubular atrophy. Borderline changes were excluded as acute cellular rejections in this study. No recipients underwent antibody-mediated rejection.

\section{Outcomes and Complications (Table 3)}

Six patients experienced cytomegalovirus reactivation revealed by cytomegalovirus antigenemia. However, no obvious invasive tissue disease occurred. One patient experienced pneumocystis pneumonia, which was treated with administration of sulfamethoxazole/trimethoprim 2 months after kidney transplantation and developed cholecystitis requiring cholecystectomy 10 months after kidney transplantation. Two patients developed lymphocele, which was treated by drainage during the perioperative period. Ten patients experienced late-onset neutropenia that was suspected to be caused by rituximab administration. They recovered from neutropenia by administration of granulocyte-colony stimulating factor and/or MMF temporary discontinuation. One patient developed carcinoma of the body and tail of the pancreas, and was treated by distal pancreatectomy with splenectomy. However, he died 20 months after transplantation. One recipient underwent postoperative diffuse pelvic hemorrhage that needed surgical intervention 
Table 3. Outcomes and complications

\begin{tabular}{|c|c|c|c|c|c|c|c|}
\hline Case & $\begin{array}{l}\text { Patient } \\
\text { survival }\end{array}$ & $\begin{array}{l}\text { Graft } \\
\text { survival }\end{array}$ & $\begin{array}{l}\text { Current eGFR, } \\
\mathrm{mL} / \mathrm{min} / 1.73 \mathrm{~m}^{2}\end{array}$ & $\begin{array}{l}\text { Acute cellular } \\
\text { rejection }\end{array}$ & $\begin{array}{l}\text { Antibody- } \\
\text { mediated } \\
\text { rejection }\end{array}$ & $\begin{array}{l}\mathrm{CMV} \\
\text { antigenemia }\end{array}$ & Other complications \\
\hline 1 & + & + & 62 & - & - & + & \\
\hline 2 & + & + & 40.96 & - & - & + & \\
\hline 3 & + & + & 44.7 & - & - & + & $\begin{array}{l}\text { Pneumocystis pneumonia, } \\
\text { cholecystitis and cholecystectomy }\end{array}$ \\
\hline 4 & + & + & 42.96 & - & - & + & Passenger lymphocyte syndrome \\
\hline 5 & + & + & 32.73 & + & - & + & \\
\hline 6 & + & + & 31.25 & - & - & - & \\
\hline 7 & - & - & & - & - & - & $\begin{array}{l}\text { Carcinoma of the body and tail of } \\
\text { the pancreas }\end{array}$ \\
\hline 8 & + & + & 34.21 & - & - & + & \\
\hline 9 & + & + & 52.39 & - & - & - & Lymphocele \\
\hline 10 & + & + & 29.22 & + & - & - & Pelvic hemorrhage \\
\hline 11 & + & + & 35.18 & - & - & - & Lymphocele \\
\hline 12 & + & + & 56.21 & - & - & - & \\
\hline 13 & + & + & 62.67 & - & - & - & \\
\hline 14 & + & + & 57.9 & - & - & - & \\
\hline
\end{tabular}

eGFR, estimated glomerular filtration rate; CMV, cytomegalovirus.

during the perioperative period. One experienced severe anemia after kidney transplantation due to passenger lymphocyte syndrome.

\section{Discussion}

Recently, ABO-incompatible kidney transplantation has become a viable treatment option in Japan [6-9]. However, there have been no reports regarding ABO-incompatible kidney transplantation for patients who developed ESKD due to diabetes nephropathy. In this single-center pilot study, both overall patient and graft survival rates were $100,89.9$, and $89.9 \%$ at 1,3 , and 5 years, respectively. Our present study demonstrated acceptable short-term outcomes of ABO-incompatible kidney transplantation in diabetic recipients, although one patient died from pancreas cancer with a functioning graft at 20 months after transplantation. To our knowledge, this may be the first demonstration of $\mathrm{ABO}$-incompatible kidney transplant outcomes in recipients with diabetes.
Our results suggested that $\mathrm{ABO}$-incompatible kidney transplantation might be an effective treatment for ESKD due to diabetes nephropathy.

It has been established that kidney transplantation is superior to remaining on dialysis for patients with diabetes [5]. Among these patients, the survival rate benefit of kidney transplantation has been reported to be significantly larger compared to that of non-diabetic patients [18]. Therefore, people with diabetes and ESKD should be actively considered for kidney transplantation as the optimal choice of renal replacement therapy. The outcomes of living donor kidney transplantation are significantly better than those of deceased donor transplantation [19]. ABO-incompatible living donor kidney transplantation may therefore be a favorable renal replacement therapy for ESKD patients with diabetes.

ABO-incompatible kidney transplantation is immunologically a high-risk procedure and requires intensive immunosuppressive therapy including plasmapheresis and/or rituximab administration $[6-9,14,15]$. Some reports have shown that there are elevated risks of infec- 
tious complications in diabetic kidney transplant recipients $[20,21]$. The risks of such infectious complications in ABO-incompatible kidney transplant recipients with diabetes may increase due to diabetic conditions and intensive immunosuppressive therapy. In our study, one patient developed pneumocystis pneumonia 2 months after kidney transplantation. Six recipients experienced cytomegalovirus reactivation revealed by cytomegalovirus antigenemia, although no obvious invasive tissue disease occurred. An effort to establish an optimal immunosuppressive protocol for diabetic ABO-incompatible kidney transplantation is necessary to minimize infectious complications while avoiding rejection in future.

A recent study demonstrated significant improvements between 1996 and 2007, with 5-year mortality rates for kidney transplant recipients with type 2 diabetes approaching those of non-diabetic recipients between 2005 and 2007 [22]. However, kidney transplant recipients with diabetes have a higher mortality than those without diabetes because of their elevated risk of cardiovascular complications and infectious complications [2,3]. Several reports demonstrated that recipients with diabetes had a higher frequency of cardiovascular events and deteriorated patient survival rates $[3,23]$. Four patients enrolled in this study had cardiovascular disease before transplantation. We routinely consult with the cardiology department for preoperative cardiac risk assessment. Whenever necessary, myocardial scintigraphy $(n=10)$ and coronary arteriography $(n=3)$ were performed. Percutaneous coronary intervention was performed before transplant in one patient. Symptomatic peripheral artery disease was treated prior to kidney transplantation, but the patients were not examined for asymptomatic peripheral artery disease. No patients underwent cardiovascular events, although the follow-up period was short. Intensive desensitization required for ABO-incompatible kidney transplantation may not cause cardiovascular events at an early post-transplant period. However, a long follow-up period is necessary to evaluate the incidence of cardiovascular events in these recipients. Interestingly, a previous report showed that the administration of rituximab led to clearly reduced plasma levels of predictors of cardiovascular disease [24].

Acute cellular rejection is considered to be a major risk factor for chronic antibody-mediated rejection which affects long-term graft survival [25]. Previous reports have shown that hyperglycemia might be associated with an increased risk of acute allograft rejection in transplant recipients with diabetes [4]. Meanwhile, Clatworthy et al. [26] suggested that B cell-related cytokines caused by rituximab administration were associated with higher rates of acute cellular rejection in rituximab-treated patients. However, there have been no reports on the relationship between hyperglycemia, administration of rituximab, and acute rejection. No antibody-mediated rejection occurred during our follow-up period, and the rate of acute cellular rejection was $14.3 \%(2 / 14)$ in this study. A previous large-sized, multicenter study revealed that the frequency of rejection treatment was $16.3 \%$ in $\mathrm{ABO}$ incompatible kidney transplantation [27], which was similar to our rate of acute cellular rejection.

Johal et al. [4] demonstrated an increased risk of developing cellular-, but not antibody-mediated, rejection among kidney transplant recipients with diabetes and revealed that diabetes at the time of kidney transplantation was independently associated with the risk of cellular rejection in a Cox regression model, adjusted for baseline variables. On the other hand, Baek et al. [28] reported that there were no significant changes in the rates of rejection between diabetic and non-diabetic recipients. Some authors suggested that patients with diabetes were rendered susceptible to cellular rejection because of their significant risk of exacerbation of glycemic control after transplantation and that strict glycemic control might be important $[4,28]$. In this study, glycemic control was relatively good because of the less than $7.0 \% \mathrm{HbA} 1 \mathrm{c}$ levels, which the Japan Diabetes Society recommends in order to avoid diabetic complications. Strict glycemic control may not have elicited acute cellular rejection in this study. Meanwhile, previous reports have shown that the administration of rituximab induces proinflammatory cytokines releases associated with regulatory $\mathrm{B}$ cell depletion. However, in ABO-incompatible kidney transplantation, any cytokine release would have been resolved by plasmapheresis and administration of steroid before transplantation [27]. Previously, we showed that acute cellular rejection in ABO-incompatible kidney transplant recipients receiving rituximab might be associated with late-onset neutropenia due to $\mathrm{B}$ cell-related cytokine release $[16,17]$. In this study, rituximab might not have affected acute cellular rejection due to the resolution of $\mathrm{B}$ cell-related cytokine storm by plasmapheresis and steroid. Further and larger researches are necessary to evaluate the frequency of rejection episodes in ABO-incompatible kidney transplant recipients with diabetes.

Although this is a pilot study, the main limitation of our study might be the small number of patients and its retrospective design. Moreover, the follow-up period was relatively short. However, to our knowledge, this is the first demonstration of clinical outcomes of ABO-incompatible kidney transplantation in diabetic recipients. 
In conclusion, kidney transplantation is considered to be the most preferred renal replacement therapy for ESKD patients with diabetes, and living donor kidney transplantation is superior to deceased donor transplantation. Therefore, ABO-incompatible kidney transplantation might be an effective treatment for ESKD due to diabetes nephropathy, although a larger, long-term follow-up study is needed to assess the safety and effectiveness of this procedure.

\section{Ethics Statement}

This study was approved by the Ethics Committee of Osaka City University Graduate School of Medicine (No. 3957).

\section{Disclosure Statement}

The authors declare no conflicts of interest.

\section{References}

1 Lim WH, Wong G, Pilmore HL, McDonald SP, Chadban SJ. Long-term outcomes of kidney transplantation in people with type 2 diabetes: a population cohort study. Lancet Diabetes Endocrinol. 2017 Jan;5(1):26-33.

2 Wiseman AC. Kidney transplant options for the diabetic patient. Transplant Rev (Orlando). 2013 Oct;27(4):112-6

3 Cosio FG, Hickson LJ, Griffin MD, Stegall MD, Kudva Y. Patient survival and cardiovascular risk after kidney transplantation: the challenge of diabetes. Am J Transplant. 2008 Mar;8(3):593-9.

4 Johal S, Jackson-Spence F, Gillott H, Tahir S, Mytton J, Evison F, et al. Pre-existing diabetes is a risk factor for increased rates of cellular rejection after kidney transplantation: an observational cohort study. Diabet Med. 2017 Aug;34(8):1067-73.

5 Wolfe RA, Ashby VB, Milford EL, Ojo AO, Ettenger RE, Agodoa LY, et al. Comparison of mortality in all patients on dialysis, patients on dialysis awaiting transplantation, and recipients of a first cadaveric transplant. N Engl J Med. 1999 Dec;341(23):1725-30.

6 Takahashi K, Saito K, Takahara S, Okuyama A, Tanabe K, Toma H, et al.; Japanese ABOIncompatible Kidney Transplantation Committee. Excellent long-term outcome of ABOincompatible living donor kidney transplantation in Japan. Am J Transplant. 2004 Jul; 4(7):1089-96.

7 Okumi M, Toki D, Nozaki T, Shimizu T, Shirakawa $\mathrm{H}$, Omoto $\mathrm{K}$, et al. ABO-Incompatible Living Kidney Transplants: Evolution of Outcomes and Immunosuppressive Management. Am J Transplant. 2016 Mar;16(3):88696.

8 Böhmig GA, Farkas AM, Eskandary F, Wekerle T. Strategies to overcome the ABO barrier in kidney transplantation. Nat Rev Nephrol. 2015 Dec;11(12):732-47.

9 Uchida J, Kuwabara N, Machida Y, Iwai T, Naganuma T, Kumada N, et al. Excellent outcomes of ABO-incompatible kidney transplantation: a single-center experience. Transplant Proc. 2012 Jan;44(1):204-9.
10 Noguchi H, Kitada H, Kaku K, Kurihara K, Kawanami S, Tsuchimoto A, et al. Outcome of renal transplantation in patients with type 2 diabetic nephropathy: a single-center experience. Transplant Proc. 2015 Apr;47(3):60811.

11 Uchida J, Machida Y, Iwai T, Kuwabara N, Iguchi T, Naganuma T, et al. Clinical outcome of $\mathrm{ABO}$-incompatible living unrelated donor kidney transplantation. Urol Int. 2011;86(3): 307-14.

12 Uchida J, Iwai T, Machida Y, Kuwabara N, Kabei K, Murao M, et al. ABO-incompatible kidney transplantation in elderly patients over 60 years of age. Int Urol Nephrol. 2012 Oct;44(5):1563-70.

13 Kosoku A, Uchida J, Kabei K, Nishide S, Shimada H, Iwai T, et al. Favorable Outcomes of Elderly ABO-Incompatible Kidney Transplantation-Pilot Single Center Experience. Urol Int. 2018;101(4):459-66.

14 Uchida J, Iwai T, Kato M, Machida Y, Naganuma T, Kumada N, et al. A novel approach to successful ABO-incompatible high-titer renal transplantation. Transplant Proc. 2008 Sep;40(7):2285-8.

15 Uchida J, Machida Y, Iwai T, Naganuma T, Kitamoto K, Iguchi T, et al. Desensitization protocol in highly HLA-sensitized and ABOincompatible high titer kidney transplantation. Transplant Proc. 2010 Dec;42(10):39984002.

16 Uchida J, Iwai T, Nishide S, Kabei K, Kuwabara N, Yamasaki T, et al. Acute Cellular Rejection in ABO-Incompatible Renal Transplant Recipients Receiving Rituximab Is Associated with Delayed-Onset Neutropenia. Ann Transplant. 2017 Jul;22:455-62.

17 Kabei K, Uchida J, Iwai T, Yamasaki T, Kuwabara N, Naganuma T, et al. Late-onset neutropenia and acute rejection in $\mathrm{ABO}$-incompatible kidney transplant recipients receiving rituximab and mycophenolate mofetil. Transpl Immunol. 2014 Aug;31(2):92-7.

18 Sørensen VR, Mathiesen ER, Heaf J, FeldtRasmussen B. Improved survival rate in patients with diabetes and end-stage renal disease in Denmark. Diabetologia. 2007 May; 50(5):922-9.
19 Guerra G, Ilahe A, Ciancio G. Diabetes and kidney transplantation: past, present, and future. Curr Diab Rep. 2012 Oct;12(5):597-603.

20 Lansang MC, Ma L, Schold JD, Meier-Kriesche HU, Kaplan B. The relationship between diabetes and infectious hospitalizations in renal transplant recipients. Diabetes Care. 2006 Jul;29(7):1659-60.

21 Abbott KC, Hypolite I, Poropatich RK, Hshieh P, Cruess D, Hawkes CA, et al. Hospitalizations for fungal infections after renal transplantation in the United States. Transpl Infect Dis. 2001 Dec;3(4):203-11.

22 Keddis MT, El Ters M, Rodrigo E, Dean P, Wohlfahrtova M, Kudva YC, et al. Enhanced posttransplant management of patients with diabetes improves patient outcomes. Kidney Int. 2014 Sep;86(3):610-8.

23 Kiberd B, Panek R. Cardiovascular outcomes in the outpatient kidney transplant clinic: the Framingham risk score revisited. Clin J Am Soc Nephrol. 2008 May;3(3):822-8.

24 Jin T, Bokarewa M, Amu S, Tarkowski A. Impact of short-term therapies with biologics on prothrombotic biomarkers in rheumatoid arthritis. Clin Exp Rheumatol. 2009 May-Jun; 27(3):491-4.

25 Nankivell BJ, Alexander SI. Rejection of the kidney allograft. N Engl J Med. 2010 Oct; 363(15):1451-62

26 Clatworthy MR, Watson CJ, Plotnek G, Bardsley V, Chaudhry AN, Bradley JA, et al. B-celldepleting induction therapy and acute cellular rejection. N Engl J Med. 2009 Jun;360(25): 2683-5.

27 Opelz G, Morath C, Süsal C, Tran TH, Zeier M, Döhler B. Three-year outcomes following 1420 ABO-incompatible living-donor kidney transplants performed after $\mathrm{ABO}$ antibody reduction: results from 101 centers. Transplantation. 2015 Feb;99(2):400-4.

28 Baek CH, Kim H, Baek SD, Jang M, Kim W, Yang WS, et al. Outcomes of living donor kidney transplantation in diabetic patients: age and sex matched comparison with nondiabetic patients. Korean J Intern Med (Korean Assoc Intern Med). 2018 Mar;33(2): 356-66.
ABO-Incompatible Kidney

Transplantation in Diabetic Patients 